\title{
Effects of the Synthetic Inertia from Wind Power on the Total System Inertia after a Frequency Disturbance
}

\author{
F. Gonzalez-Longatt ${ }^{1}$, E. Chikuni ${ }^{2}$, E.Rashayi $^{3}$ \\ ${ }^{1}$ Department of Aerospace, Electrical and Electronic Engineering, Coventry University, Kingdom \\ ${ }^{1}$ Email: fglongatt@ieee.org \\ ${ }^{2}$ Department of Electrical Power Engineering, Cape Peninsula University of Technology, South Africa \\ ${ }^{2}$ Email: chikunie@cput.ac.za \\ ${ }^{3}$ Department of Electrical Engineering, University of Zimbabwe \\ ${ }^{3}$ Email: Rashayi@gmail.com
}

\begin{abstract}
The future power systems face several challenges; one of them is the use of high power converters that virtually decouple primary energy source from the AC power grid. An important consequence of this situation is their effect on total system inertia and the ability to overcome the system's frequency disturbances. The wind power industry has created a controller to enable inertial response on wind turbines generators: Synthetic Inertial. This paper evaluates the effects of the inertia emulation of wind turbines based on full-converters and their effect on total system inertia after frequency disturbances happen. The main contribution of this paper is to demonstrate (based on simulations) that during an under-frequency transients on future power systems, synthetic inertia does not completely avoid worse scenarios in terms of under-frequency load shedding. The extra power delivered from a wind turbine during frequency disturbances can increase "momentary" the total system inertia and substantially reduce the rate of change of frequency providing time for the active governors to respond. However, synthetic inertia might not completely avoid under-frequency load shedding.
\end{abstract}

\section{INTRODUCTION}

Future power systems face several challenges [1]: (i) the high penetration level of renewable energy from highly variable generators connected over power converters, (ii) several technologies for energy storage with very different time constants, some of them using power converters as an interface to the grid, (iii) A complex European transmission network facilitating the integration of large-scale renewable energy sources and the balancing and transportation of electricity based on underwater multi-terminal high voltage direct current (MTDC) transmission. All of them have an element in common, high power converters that decouple the new energy sources from the pre-existent AC power systems [1], [2].

During a system frequency disturbance the generation/demand power balance is lost, the system frequency will change at a rate initially determined by the total system inertia. However, future power systems will increase the installed power capacity (MVA) but the effective system inertial response will stay the same as at present. This is because the new generation units based on power converters create a decoupling effect of the real inertia and the ac grid [1]. The result is deeper frequency excursions of system disturbances. If considerable reduction in the ability to overcome system frequency's disturbances is expected, the inertia response may be decreased. The inertial response of the system might be negatively affected with devastating consequences for system security and reliability [1].

The aim of this paper is to evaluate the effects of synthetic inertia on wind turbines based on full-converters on the total system inertia after a frequency disturbance. This paper is organized as follows: Section II describes the frequency response on power system after a frequency disturbance. Section III presents the concept of synthetic inertia and show two approaches used on WT (wind turbine) controller to create inertial responses. Section IV address aspects related to system inertia, system frequency response and some potential challenges for futures networks. Section $\mathrm{V}$ the results of simulations that define the impact of synthetic inertia on the protection/control schemes over a test system. Finally, the advantages of this novel application are discussed at the conclusions.

\section{FREQUENCY RESPONSE}

The system frequency of a synchronous power system varies with the imbalance of energy supplied and the electrical energy consumed [3], [4]. When large generating blocks are lost, the system undergoes a frequency swing that depends on to the size of the loss. Limits imposed on the magnitude of frequency deviation prevent system collapse [5]. In accordance with the Electricity Supply Regulations 1989 and hence the National Grid Company's (NGC) Transmission License, the frequency delivered to the consumer must not vary from the declared value by more than $\pm 1 \%[6]$.

In the event of a sudden loss of generation or sudden connection of a large load, the system frequency starts dropping (Region I of Fig. 1) at a rate mainly determined by the total angular momentum of the system $M_{\text {total }}$, sum of the angular momenta of all generators $\left(M_{g, i}\right)$ and spinning loads connected to the system $\left(M_{L, i}\right)$. 


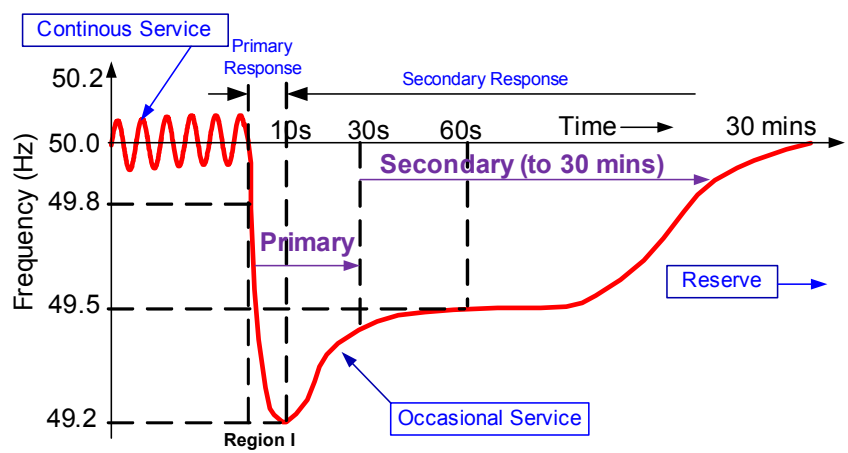

Fig. 1. General Frequency System Response and Controller involved: The operational limits show on the figure correspond to England and Wales.

In the case where the frequency drops by more than 0.2 $\mathrm{Hz}$, generation plants are contracted to provide additional frequency response duties.

Large frequency disturbances, particularly trips of large generation plants, cause generation-demand unbalance that must be corrected by frequency control loops. These controllers are provided in order improve the System Frequency Response (SFR). The frequency controllers cover multiple time-frames [1]: (i) inertial response also know as fast primary response, (ii) governor response also known as slow primary response, (iii) automatic generation control (AGC), and (iv) tertiary control. These controllers define the dynamic changes associated to $S F R$. [3]. These services are illustrated in Fig. 1 (tertiary control is not illustrated).

\section{SYNTHETIC INERTIA}

The frequency of a power system depends on real power balance: generation-demand. In the standard operation of a power system, the frequency is regulated within strict limits by adjusting the electrical supply to meet the demand. If the balance between generation and demand is not reached, the system frequency will change at a rate initially determined by the total system inertia. The total system inertia comprises the combined inertia of most of spinning generation and load connected to the power system.

\section{A. Inertia constant and Swing Equation}

The inertia constant of a rotating system $(H)$, or individual generator, is used to define the energy stored in its rotating mass $\left(E_{c 0}\right)$. This definition consists of the time, in seconds, that it would take to replace this stored energy when operating at rated mechanical speed $\left(\omega_{s m}\right)$ and rated apparent power output $\left(S_{\text {base }}\right)[3]$, [7]:

$H=\frac{1}{2} \frac{J \omega_{s m}^{2}}{S_{\text {base }}}$

where: $J$ is the total moment of inertia in $\mathrm{kg} \cdot \mathrm{m}^{2}, \omega_{s m}$ is the rated mechanical speed in $\mathrm{rad} / \mathrm{s}$, and $S_{\text {base }}$ is the selected base apparent power in MVA.

A change in the generation/load balance, at one point in the system will be reflected throughout the system by a change in frequency. The relationship between the power imbalance at the terminals of the $i$-th generator in p.u. $\left(\Delta p_{i}\right)$ and its frequency $\left(f_{i}\right)$, can be expressed as:

$\frac{2 H_{i}}{f_{n}} \frac{d f_{i}}{d t}=p_{m, i}-p_{e, i}=\Delta p_{i} \quad i=1,2, \ldots, N$

where: $p_{m, i}$ is the mechanical turbine power in p.u., $p_{e, i}$ is the electrical power in p.u., $\Delta p_{i}$ is the load generation imbalance in p.u., $H_{i}$ is the inertia constant in s, $f_{i}$ is the frequency in $\mathrm{Hz}$, $f_{n}$ is the nominal system frequency in $\mathrm{Hz}$ and $d f_{i} / d t$ is the rate of change of frequency in $\mathrm{Hz} / \mathrm{s}$. This is a simplified version of the swing equation, which assumes that any damping effects during the disturbance are relatively small.

It follows, therefore, that if the instant of the disturbance is known $\left(t=t_{0}\right)$, and the size of the power imbalance, $\Delta p_{i}\left(t_{0}\right)$, and the rate of change of frequency (ROCOF), $d f_{i} / d t$ at the terminal of the $i$-th generator are known, then the unknown inertia constant of this generator can be estimated $\left(\hat{H}_{i}\right)$ using (2):

$$
\hat{H}_{i}=\frac{\Delta p_{i}\left(t_{0}\right) f_{n}}{\left.2 \frac{d f_{i}}{d t}\right|_{t=t_{0}}}
$$

It must be noted that (3) is only valid immediately after a disturbance, a time referred to as $t=t_{0}{ }^{+}$. After this time other factors, not accounted for in equation (3), begin to affect the dynamic behavior of the system. The ROCOF can be simply determined from two consecutive measurements:

$\left.\frac{d f_{i}}{d t}\right|_{t=t_{0}} \cong \frac{f_{i}\left(t_{0}^{+}\right)-f_{i}\left(t_{0}^{-}\right)}{t_{0}^{+}-t_{0}^{-}}$

where $f_{i}\left(t_{0}^{+}\right)$and $f_{i}\left(t_{0}{ }^{-}\right)$are the frequency in $\mathrm{Hz}$ sampled after and before the disturbance, and $t_{0}^{+}$and $t_{0}^{-}$represent the corresponding sampling times. All of these values refer to the $i$-th generator. The power imbalance, $\Delta p_{i}$, can be defined in terms of mechanical $\left(P_{m, i}\right)$ and electrical power $\left(P_{e, i}\right)$ :

$\Delta p_{i}\left(t_{0}\right) \approx p_{e, i}\left(t_{0}^{-}\right)-p_{e, i}\left(t_{0}^{+}\right)$

Using (3)-(5) the inertia constant of the $N$ generators in the system can be calculated.

The total system inertia $\left(H_{T}\right)$ comprises the combined inertia of most of spinning generation and load connected to the power system.

\section{B. Synthetic Inertia: Concept}

If during a system frequency disturbance the balance between generation-demand is not reached, then the system frequency will change at a rate initially determined by the total system inertia $\left(H_{T}\right)$. The total system inertia comprises the combined inertia of most of spinning generation and load connected to the power system. The contribution of the 
system inertia of a load or generator is dependent on whether the system frequency causes changes in its rotational speed and, therefore, its kinetic energy.

The power associated with this change in kinetic energy is fed or taken from the power system and is known as the inertial response [8]. During a system frequency event the total system inertial response of all electrical machines connected to the system is the main factor that determine the initial ROCOF. For a robust power system (system frequency is not overly sensitive to the power imbalances), it is extremely important that a large proportion of generation and load connected to the power system contributes to the total system inertia and then provide inertia response.

Modern WTGs (wind turbine generators) use power electronics converters to enable variable speed operation in order to capture wind energy over a wide range of speeds. However, these converters isolate the rotational speed from the system frequency so WTG based on back-to-back $\mathrm{AC} / \mathrm{DC} / \mathrm{AC}$ converters offer no natural response to system frequency [9], [10]. In this paper, the adjective "natural" on the previous sentence is used because some manufacturers have started to integrate controllers on modern WTG's in order to provide inertial response (and governor response on some cases) for large, short-duration frequency deviations. The Wind turbine industry has created several names for this control system that enable inertial responses on a WTG: Artificial, Emulated, Simulated, or Synthetic Inertial. Examples of synthetic inertia controlled commercially available for WTG are: General Electric WindINERTIA ${ }^{\mathrm{TM}}$ [11], [12] ENERCON Inertia Emulation [13].

The objective of the synthetic inertia control is to extract stored inertial energy from the moving part on WTGs. The idea is to produce incremental energy similar to that provided by a synchronous generator with real inertia. Synthetic inertia controllers are based on two different approaches: (i) Releasing "hidden" inertia and (ii) Reserve capacity in pitch.

To release the "hidden" inertia a controller to the takes kinetic energy from the wind turbine (WT)'s rotating mass. A controller based on this concept increases the electric power output during the initial stages of a significant downward frequency event. The active power (inertial power, $\Delta p$ ) of the control is achieved by:

$$
\Delta p=2 H_{s y n} \times f_{s y s} \times \frac{d f_{s y s}}{d t}
$$

where $H_{s y n}$ express the synthetic inertia (sec) and $f_{\text {sys }}$ system frequency (p.u). Implementation of releasing hidden inertia controllers is depicted on Fig. 2.

Traditional variable speed WTs are designed to always operate at the maximum power point tracking (MPPT) so they have no power reserve to support frequency control in the steady state. Reserve capacity in pitch concept coerces a wind standby power by maintaining reserve capacity in pitch. A de-loading controller enable the WT to operate over deloading curves instead of MPPT and saves the available power as reserve by using a pitch controller (pitching) or increasing the rotational speed from the MPPT value (overspeeding). These concepts are well understood and therefore will not be discussed further in this paper.

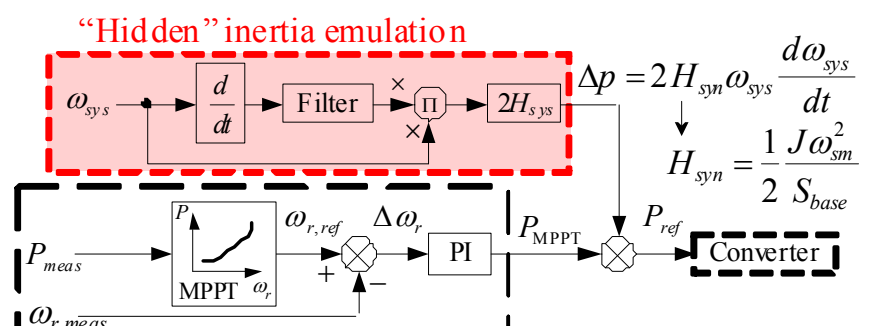

$\bigsqcup^{\omega_{\text {r,meas }}}-\longleftarrow-\downarrow$

Fig. 2. General Scheme for Releasing "Hidden" Inertia Controller

\section{IV.SIMULATIONS AND RESULTS}

This section presents simulations and results considering a Test System representative of a future network which can be obtained from [1]. This system consists of 8-generator, 8-bus, 7-load, and 22-transmission lines and it has been divided in seven areas. DIgSILENT ${ }^{\circledR}$ PowerFactory $^{\mathrm{TM}}$ is used for timedomain simulations and DIgSILENT Simulation Language (DSL) is used for dynamic modeling.

The system has a total generation of $100.736 \mathrm{GW}$ and a total load of $96.75 \mathrm{GW}$ and Fig. 3 shows steady state conditions for case base where a power flow of about $15 \mathrm{GW}$ from the Top to Tail is depicted.

In this paper, the operational-control criteria used for system frequency analysis is based a specific criteria defined by the author, it is mainly an adapted version of the GB Security and Quality of Supply Standards (GB SQSS). The following assumptions are used in this paper:

(i) the level of infrequent loss of power infeed is set-up to $1.800 \mathrm{GW}$, and frequency response must avoid a deviation of system frequency outside statutory limits: range $49.8 \mathrm{~Hz}$ to $50.2 \mathrm{~Hz}$ for more than 5 cycles,

(ii) frequency control devices (or speed governor) are set up to operate with an overall speed Droop of 4\% (GB SQSS establishes between 3 and 5\%),

(iii) Under Frequency Load Shedding (UFLS) is set to start at $49.8 \mathrm{~Hz}$ and the plan consists of six load shedding steps of equal size $\Delta p_{\text {shed }}$ [14]. A delay for each load shedding step is $t_{d}=0.1 \mathrm{~s}$ ( 5 cycles).

Fig. 4 depicts the general structure of variable-speed wind turbine with a direct-drive permanent magnet synchronous generator (PMSG). The models used for back-to-back converter, detail of each model are taken from: [15], [16]. The parameter used for these models are escalated to simulate an equivalent $5 \mathrm{MW}$ wind turbine. 


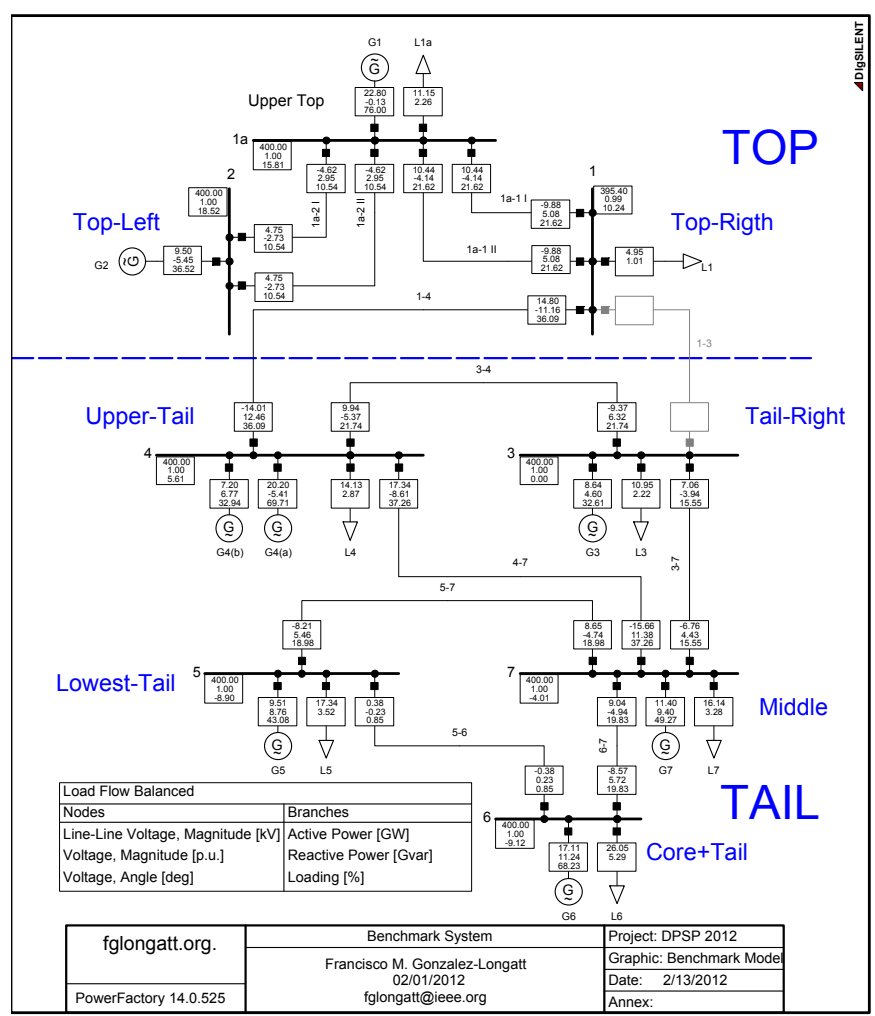

Fig. 3. Test Case: "TOP-TAIL" System: Steady-State Conditions

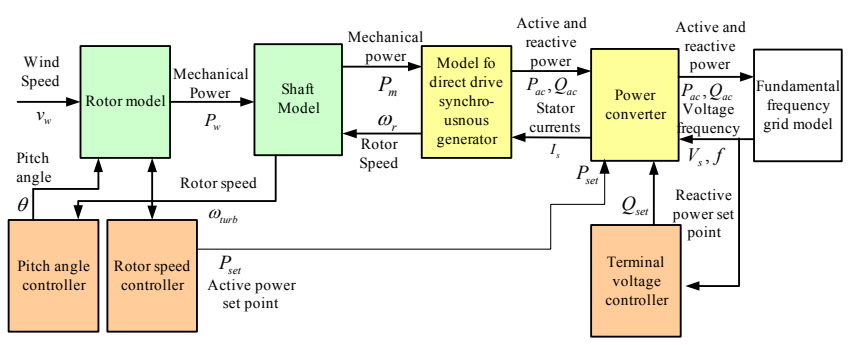

Fig. 4. General structure of a model of a variable-speed wind turbine with a direct-drive synchronous generator and full power converter

\section{Results and Discussion}

An infrequent loss of infeed is used as system frequency disturbance; it consists of tripping one generating unit connected to Upper-Tail area at $t=1.0$ s (generator G4(b) on Fig. 3). Four generators providing governor frequency response and three conventional generators (G2, G5, and G7) will be operating without active governors or at maximum power. Fig 5 shows the plots of the system response for base case considering an exceptional loss of power infeed, the UFLS is not active in this case and the frequency nadir reaches $f_{\min }=49.259 \mathrm{~Hz}$ at $t_{\min }=6.602 \mathrm{~s}$, Fig 5 (a).

The impact of synthetic inertia $\left(H_{s y n}\right)$ provided by WT into the total system inertia $\left(H_{T}\right)$ is quantitatively analyzed through time-domain simulations. Several levels of loss of power infeed from 0.3 to $3.2 \mathrm{GW}$ are simulated and rate of change of frequency (ROCOF) of the frequency of inertia centre $\left(f_{c}\right)$ is plotted on Fig. 6. Fig. 7 shows the total system inertia $\left(H_{T}\right)$ considering the increases on the loss of generation infeed. The ROCOF and the minimum frequency (nadir) increases as the level of loss of power infeed increase and the total system inertia is kept constant. The small deviations of the total system inertia are consequence of numerical error during the inertia estimation method presented on Section III.A, the overall error is less than $0.0006 \mathrm{~s}$.

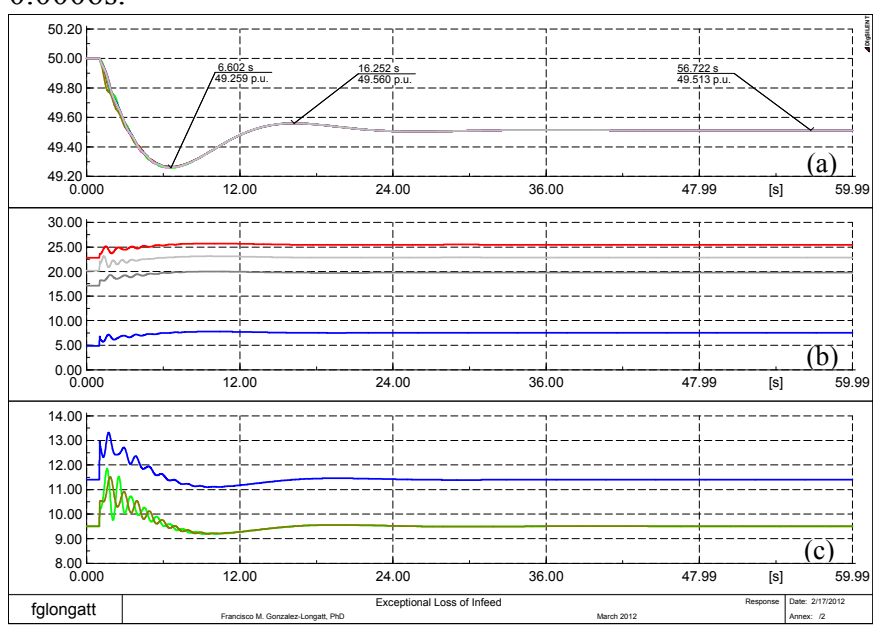

Fig. 5. System Frequency response to an exceptional loss of generation infeed (a) Frequency in $\mathrm{Hz}$, Generation active power in GW (b) with and (c) without frequency response.

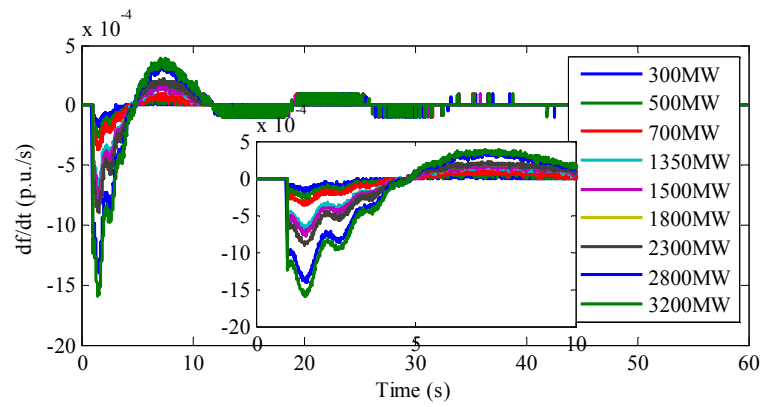

Fig. 6. ROCOF (p.u/s) considering level of loss of power infeed: Base Case.

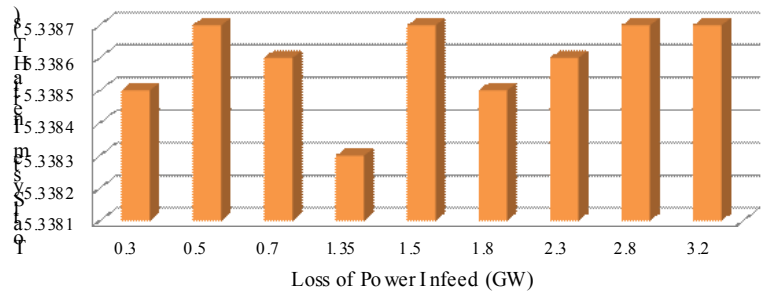

Fig. 7. Total System Inertia $\left(H_{T}\right)$ considering level of loss of power infeed: Base Case.

An exceptional loss of power infeed triggers a substantial excursion on the system frequency. The ROCOF for each 
generation unit is shown on Fig 8, and Fig 9 shows the inertia constant of each generator $\left(H_{i}\right)$ is calculated using the estimation method presented in Section III.A. The exceptional loss of power infeed produce a frequency nadir of it is more than $741 \mathrm{mHz}$ and persist for more than 5 cycles (see Fig. 8 and Case I).

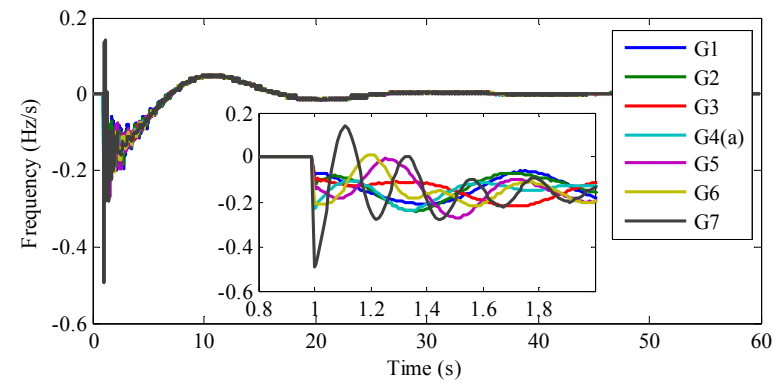

Fig. 8. ROCOF (Hz/s) considering an exceptional loss of power infeed: Base Case.

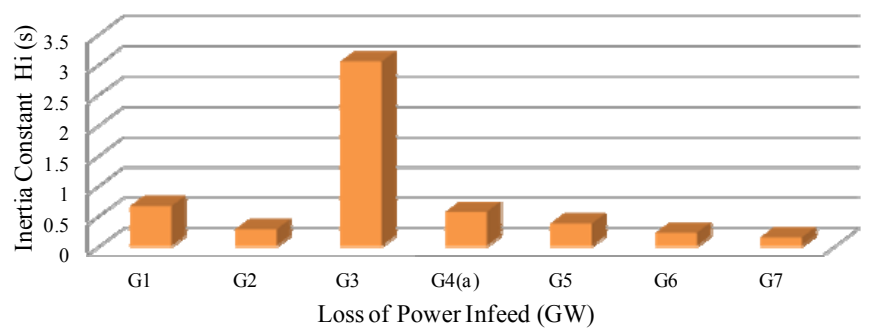

Fig. 9. Generator Inertia Constant $\left(H_{i}\right)$ considering an exceptional loss of power infeed: Base Case.
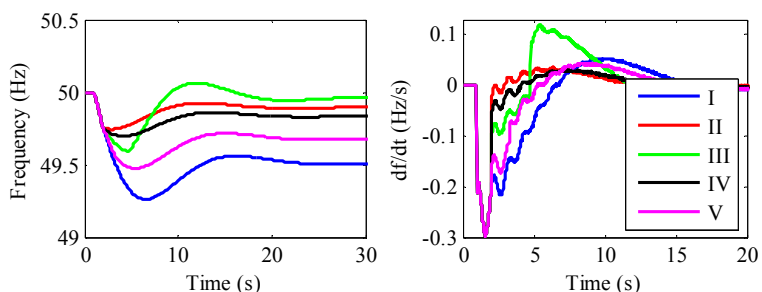

Fig. 9. System Frequency $\left(f_{c}\right)$ and ROCOF $(\mathrm{Hz} / \mathrm{s})$ considering different UFLS schemes: Base Case. $\Delta p_{\text {shed }}=20 \%$.

ULFS is activated to avoid a prohibitive frequency nadir and to allow the integration of the wind power. Several UFLS schemes on demand side of Tail area are tested, loads: L4, L5, L6, L7 (see Fig. 3). Initially, a UFLS scheme base on six load shedding steps of equal size $\Delta p_{\text {shed }}=20 \%$ is examined, the results of system frequency and ROCOF are shown on Fig. 9 (load shedding Case I: $0 \mathrm{GW}$, II: 2.8260GW, III: $6.2940 \mathrm{GW}, \mathrm{IV}: 5.7520 \mathrm{GW}, \mathrm{V}: 7.3660 \mathrm{GW})$.

A cluster of wind farm is connected on bus 3 at Tail-Right area and it is generating $30 \mathrm{GW}$ and control loop for releasing "hidden" inertia $\left(H_{s y n}=3.75 \mathrm{~s}\right)$ is included. Benefits of the integration of this wind farm include the increase on 164 $\mathrm{mHz}$ the minimum frequency during at exceptional loss of power infeed. A better evaluation include vary the value of the synthetic inertia provided by the wind farm, values from 0.1 to $10.0 \mathrm{~s}$ has been conceded the system frequency $\left(f_{c}\right)$ ROCOF are plotted on Fig 9 and the total system inertia results are shown on Fig. 10 .
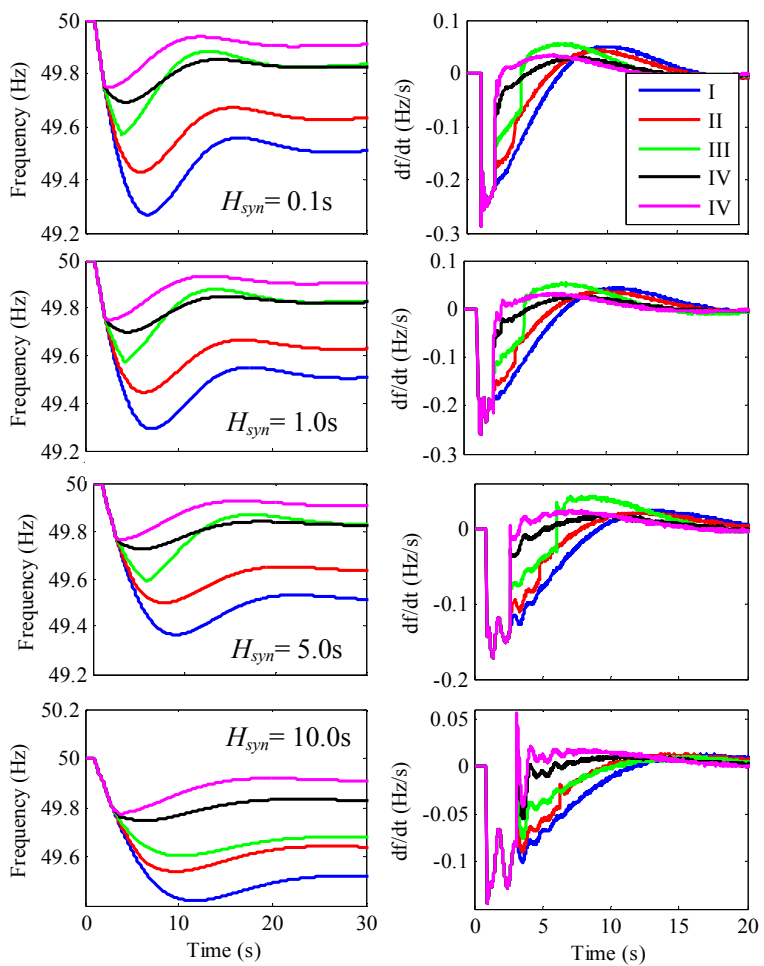

Fig. 9. System Frequency $\left(f_{c}\right)$ and ROCOF $(\mathrm{Hz} / \mathrm{s})$ considering different UFLS schemes: Wind Integration $\left(H_{\text {syn }}\right) . \Delta p_{\text {shed }}=20 \%$.

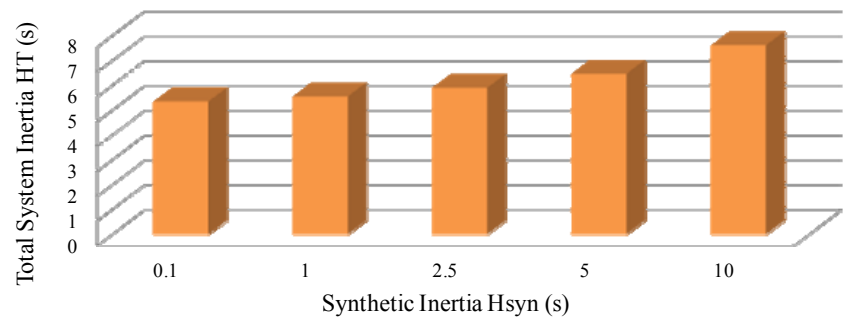

Fig. 10. Total System Inertia $\left(H_{T}\right)$ considering different UFLS schemes: Wind Integration considering several values of Synthetic Inertia $\left(H_{s y n}\right)$.

An increase on the synthetic inertia increases the total system inertia and the increase depends on the value o the synthetic inertia. This is a very positive effect and it is independent from the load shedding scheme used. This increase on the total system inertia is consequence of the active power contribution during the inertial response, as consequence the ROCOF at the very beginning of the dynamic process is decreased (considering the same loss of generation infeed). 


\section{Discussion: Impact on the Load Shedding Schemes}

Synthetic inertia changes the total system inertia and this situation has two important consequences on the underfrequency protection schemes: (i) reduce the system frequency exclusion and the minimum frequency reached after the disturbance, and (ii) change the ROCOF.

These effects are evaluated considering changes on the synthetic inertia $\left(H_{s y s}=0.1,1.0,2.5,5.0\right.$ and $\left.10.0 \mathrm{~s}\right)$ and the step size of the load-shedding $\left(\Delta p_{\text {shed }}\right)$ are varied on the UFLS scheme: $1 \%, 2.5 \%, 5 \%, 10 \%$ and $20 \%$ (see Fig. 11 )
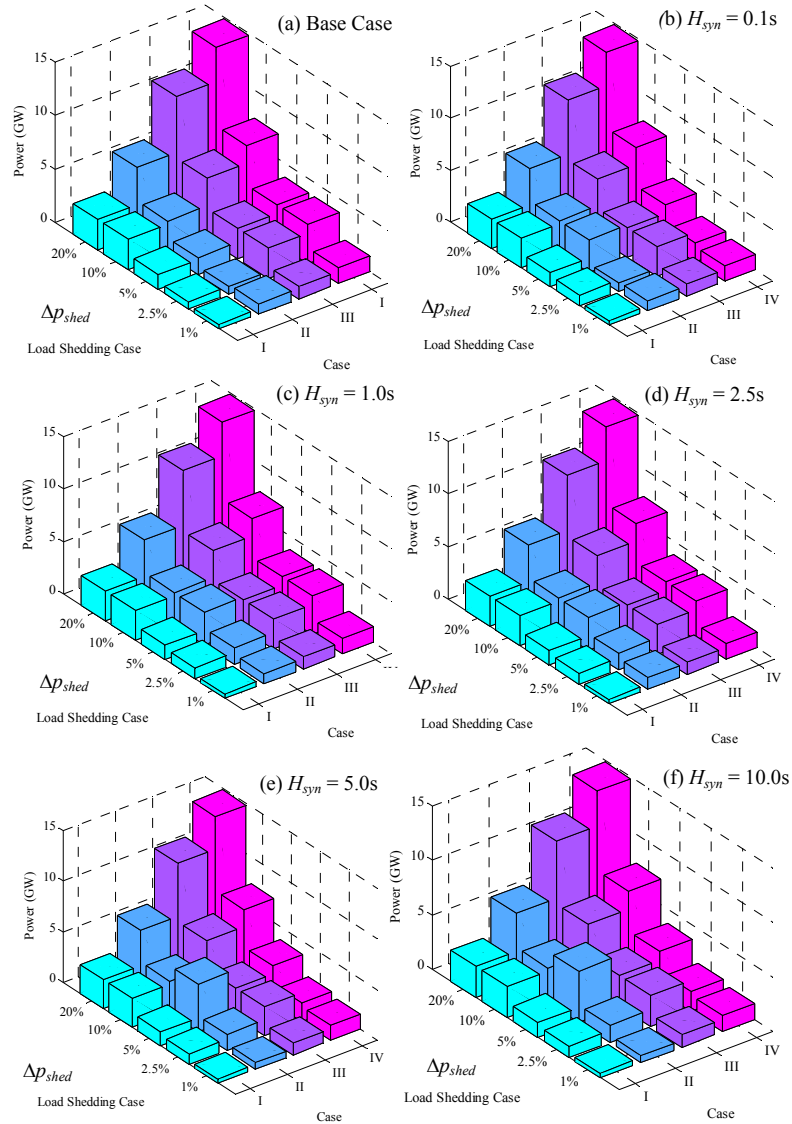

Fig. 11. Power shed (GW) considering different UFLS schemes $\left(\Delta p_{\text {shed }}\right)$ : Wind Integration considering several values of Synthetic Inertia $\left(H_{\text {syn }}\right)$.

Synthetic inertia not completely avoid the ULFS for system frequency disturbances like an exceptional loss of power infeed however there are two important aspects: (i) increases of synthetic inertia values and moderate to small step size on the setting on the UFLS might decrease the total power during the load shedding and, (ii) increases on the synthetic inertia might delay the operation of the underfrequency protection schemes. The last conclusion is depicted on Fig. 9 where the delay is observed for the second trip of the UFLS on Case III for synthetic inertia less than 10s, in the particular case of $H_{s y n}=10 \mathrm{~s}$, the second operation of UFLS is avoided. Fig 12 shows the operation of the UFLS, special details is presented for the second trip, the time delays on the trips is observed between the system considering a synthetic inertia of 1.0 and $2.5 \mathrm{~s}$.
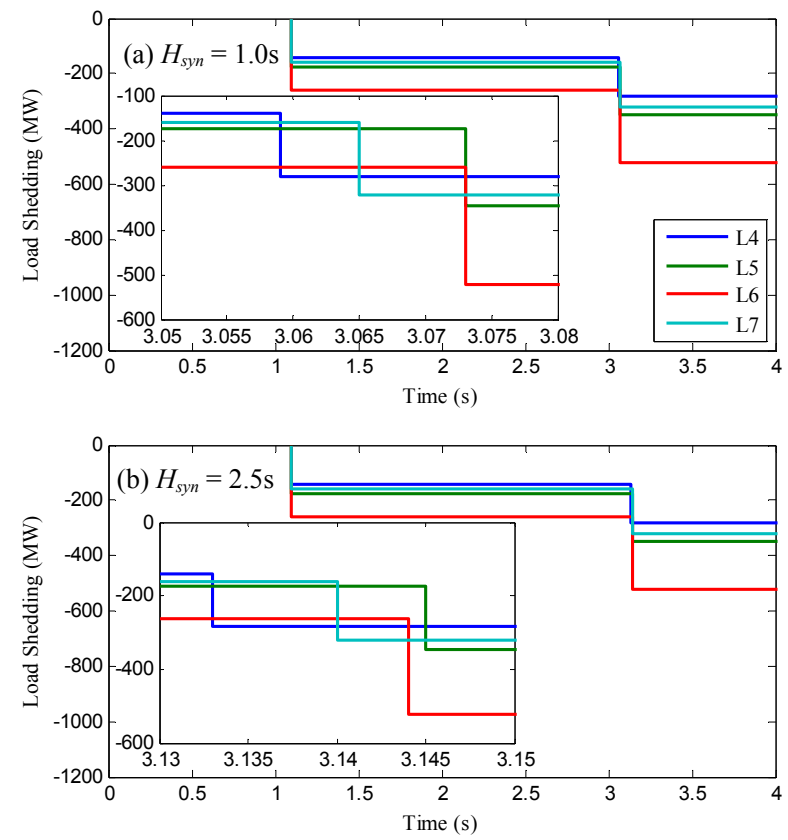

Fig. 12. Power shed (GW) considering different a UFLS of six step $\Delta p_{\text {shed }}=$ $1 \%, T_{\text {delay }}=0.1 \mathrm{~s}$. Wind Integration considering $H_{\text {syn }}=1.0 \mathrm{~s}$ and $2.0 \mathrm{~s}$. Case IV: UFLS relays on L4, L5, L6 and L7.

\section{E. Discussion: Impact on the WT Power Converter}

The hidden inertia reduces the maximum ROCOF and increase the frequency nadir, and this mechanism of inertia emulation is based on release the kinetic energy of the rotating masses on the WT. This mechanism has two important consequences that require to be carefully be evaluated: (i) the variable speed wind turbines have a lower inertia than classical synchronous generators, as consequence the value of the synthetic inertia must be correctly defined to avoid an potentially dangerous decrease on the rotational speed with all the consequences on the drive train, and (ii) releasing the hidden inertia imply a sudden increase on the electrical power output as consequence the full power converter must provided this sudden increase of current.

Old wind turbines did not include controllers to provide synthetic inertia. However an upgrade of the power control loops allows this feature, and special evaluations are required in order to avoid a fatal failure on the wind turbine systems. The power devices used on power converter are quite sensible to changes on the electrical variables, the synthetic inertia imposes electrical transient conditions which must be evaluated and it is especially true during the inertia release period and the recovery period. 


\section{V.CONCLUSIONS}

This paper evaluates the effects of the inertia emulation of wind turbines based on full-converters and their effect on total system inertia after a frequency disturbances happen. The substantial effect of synthetic inertia is on total system inertia and system inertial response: (i) the extra power delivered from WT can substantially reduce the ROCOF (ii) it provides time for the active governors to respond. However a coordination between controllers looks desirable (iii) increasing synthetic inertia helps to delay the UFLS and avoid repeated operations at exceptionally high values of synthetic inertia, (iv) synthetic inertia might not completely avoid UFLS, (v) ROCOF immediately after a system disturbance is independent on the UFLS scheme, (vi) UFLS helps to reduce the negative recovery effect caused by synthetic inertia. The main contribution of this paper is to demonstrate the potential positive effect on the total system inertia on future power systems that integrate synthetic inertia, however the under-frequency protection schemes must be rethought because synthetic inertia cannot completely avoid worse scenarios in terms of UFLS.

\section{REFERENCES}

[1] F. Gonzalez-Longatt, "Impact of Synthetic Inertia from Wind Power on the Protection/Control Schemes of Future Power Systems: Simulation Study," presented at the DPSP 2012 - Protecting the Smart Grid, The 11th International Conference on Developments in Power System Protection, Birmingham, United Kingdom, 2012.

[2] F. Gonzalez-Longatt;, P. Regulski;, H. Novanda;, and V. Terzija; "Impact od Shaft Stiffness on Inertial Response of Fixed Speed Wind Turbines," Automation of Electric Power Systems, vol. 36, pp. 191-197, 2012.

[3] J. Machowski, J. W. Bialek, and J. R. Bumby, Power System Dynamics: Stability and Control, 2nd ed. ed. Oxford: John Wiley, 2008.

[4] B. Pal and B. Chaudhuri, Robust control in power systems. New York: Springer, 2005.

[5] GB. (2009). Security and Quality of Supply Standard (SQSS). Available: $\mathrm{http} / / / \mathrm{www}$. nationalgrid.com/uk/Electricity/Codes/gbsqsscode/

[6] L. Holdsworth, J. B. Ekanayake, and N. Jenkins, "Power system frequency response from fixed speed and doubly fed induction generator-based wind turbines," Wind Energy, vol. 7, pp. 21-35, 2004.

[7] P. Kundur, N. J. Balu, and M. G. Lauby, Power system stability and control. New York; London: McGraw-Hill, 1994.

[8] A. Mullane, G. Bryans, and M. O'Malley, "Kinetic energy and frequency response comparison for renewable generation systems," in Future Power Systems, 2005 International Conference on, 2005, pp. 6 pp.-6.

[9] G. Lalor, A. Mullane, and M. O'Malley, "Frequency control and wind turbine technologies," Power Systems, IEEE Transactions on, vol. 20, pp. 1905-1913, 2005.

[10] S. Yuan-zhang, Z. Zhao-sui, L. Guo-jie, and L. Jin, "Review on frequency control of power systems with wind power penetration," in Power System Technology (POWERCON), 2010 International Conference on, 2010, pp. 1-8.

[11] N. Miller, K. Clark, and R. Walling, "WindINERTIA: Controlled Inertial Response from GE Wind Turbine Generators," presented at the 45th Annual Minnesota Power Systems Conference, Minneapolis, Minnesota, 2009.

[12] N. W. Miller, K. Clark, and M. Shao, "Frequency responsive wind plant controls: Impacts on grid performance," in Power and Energy Society General Meeting, 2011 IEEE, 2011, pp. 1-8.

[13] S. Wachtel and A. Beekmann, "Contribution of Wind Energy Converters with Inertia Emulation to Frequency Control and Frequency Stability in Power Systems," presented at the 8th International Workshop on Large-Scale Integration of Wind Power into Power Systems as well as on Transmission Networks for Offshore Wind Farms, Bremen, Germany, 2009.

[14] P. M. Anderson and M. Mirheydar, "An adaptive method for setting underfrequency load shedding relays," Power Systems, IEEE Transactions on, vol. 7, pp. 647-655, 1992.

[15] F. González-Longatt, P. Wall, and V. Terzija, "A Simplified Model for Dynamic Behavior of Permanent Magnet Synchronous Generator for Direct Drive Wind Turbines," in IEEE PES Trondheim PowerTech 2011, Trondheim, Norway, 2011.

[16] S. Achilles and M. Poller. Direct drive synchronous machine models for stability assessment of wind farm. Available: http://www.digsilent.de/Consulting/Publications/DirectDrive_Modeling .pdf 